\title{
Exchange of Paint in Hit \& Run Collisions and Its Significance as Forensic Evidence
}

\author{
Ajay Kumar* \\ Assistant Director (Scene of Crime), India
}

Submission: February 23, 2018; Published: March 01, 2018

*Corresponding author: Ajay Kumar, Assistant Director (Scene of Crime), O/o Inspector General of Police Hisar Range Hisar, Tel: 09996088880; E-mail. ajayadsoc@gmail.com

\section{Abstract}

Generally there are no eyewitnesses in hit-and-run cases, so physical evidence becomes all important for the solution of the crime which depends on the recognition, protection; selection, identification, and evaluation of the transferred/exchanged material i.e. paint. In a hit and run case usually mutual exchange of paints takes place between the criminal's vehicle and the victim's vehicle involved in collision. It links the accused vehicle with the crime and with the vehicle of victim. On the other hand, if the clues recovered, do not link the suspect vehicle with the victim's or the scene of occurrence, the innocence of the suspect is established, thus helps the innocent. Until the paint evidence can be forensically examined, it should be carefully preserved so that it remains unaltered while it is transferred from the crime scene to the laboratory. This paper will review the significance of paint as forensic evidence with relevant case studies, and discuss how it can be collected and preserved for forensic examination.

\section{Introduction}

When most of us think about paint, we think about putting colours on our walls or choosing a paint colour for our vehicles. However, paint can be powerful forensic evidence, or evidence that can be utilized to solve crimes. Like glass, fibers, blood and hair, paint is considered to be trace evidence. In our case studies, the paint transferred from the one vehicle to other vehicle and vice versa played conclusive role as forensic evidence; giving investigators a good immediate clue as to the colour of the vehicle they're looking for. Paint is a pigmented polymer that is applied and adheres to various surfaces. Paint evidence may be found when paint has been transferred from one surface to another i.e. in a hit and run case when one vehicle hits another and ran away from the scene of collision; there may be an exchange of paint between the vehicles involved. The analysis of paint evidence takes place in a forensic science laboratory. Microscopic as well as chemical tests are to be conducted to make sure the paint did originate at the victim's vehicle/suspect's vehicle $[1,2]$.

From the sequence of the paint evidence on the suspect vehicle the investigators could hypothesize that the suspected vehicle had hit the victim's vehicle. Moreover, Investigators must look for several things such as the edges of the paint sample, and whether or not there are multiple layers of paint present beyond the surface layer. This could help police determine if the culprit's car is newer or older, as a paint chip from a car that has been painted several times over the years is likely to have multiple paint layers. So this paper enunciates about how to establish the identity of culprit vehicle with the victim vehicle through paint as trace evidence in a hit and run case [3].

\section{Material and Methods}

Paint chips and smears are frequently left as physical evidence at hit and run crime scenes as well as in other accidental cases during which it may be transferred from one vehicle to another or from a vehicle to a person who has been struck. In order to collect and preserve paint evidence, it is started with securing the scene of the crime. Prior to the collection of a paint sample, the area containing the sample is photographed without disrupting the evidence. Hence, investigating officer must keep in mind that any disruption to the crime scene area could potentially contaminate the paint evidence as other trace evidences do. Investigators can then proceed to collect the paint sample, typically by carefully scraping or peeling the paint from the surface area where it was located. So investigating officer must be competent and effective in collecting paint evidence and he must be aware of the importance of paint as physical evidence Tools such as tweezers might be used during the collection process. There are several steps in the systematic investigation involving collection of paint as physical evidence; all of these are to be followed and never go for shortcuts:

a. Collect standard paint from the victim's vehicle. Collect standard paint from the suspect's vehicle also. The standard samples must include all layers of paint down to the metal or base surface of the vehicle. If the paint can be flaked off by bending the surface slightly, remove it in this manner. If not, cut the paint off using a clean knife blade, or razor blade. Use a new blade for each sample collected, if possible. If not, thoroughly clean the blade between samples. 


\section{Journal of Forensic Sciences \& Criminal Investigation}

b. Collect paint transferred onto the victim's vehicle and also paint transferred onto the suspect's vehicle. If possible, flake off loose chips of paint from damaged areas on the vehicle that contain visible smears of paint. If it is not possible to flake off chips, then attempt to cut around the areas with the smears using a clean, sharp blade taking care to keep the smears intact and to include the original surface containing the smear. Keep all transfers recovered from different areas in separate containers.

c. Vehicle often contain multiple layers of paint, not all of which may transfer. As an example, vehicles often have a clear coat as the top layer and this layer may be the only one that transfers. Additionally, different parts of a vehicle may contain different paint even though the paint in these areas appears to be the same colour. Therefore, all areas showing any damage should be sampled [4-6].

d. When paint sample scraped off, in order to preserve the layer structure of the paint during the investigation of the hit and run case; the entire vehicle components (e.g. bumper) that contain paint evidence. All paint samples should be kept in separate containers. Package all the physical evidences in pill boxes or glass vials or slide boxes separately and seal them properly. Plastic bags, cotton, or envelopes should not be used.

e. Remember to use caution in the collection of glass evidence. Adding your blood to the evidence and to the crime scene can only confuse the issue.

f. If paint evidence is found on clothing, it should not be removed. Rather, the clothing should be rolled up in paper and sent to the lab.

g. Additional evidence may also be present and should be collected. Examples of such evidence are automotive parts, glass, and plastic lens pieces at a hit-and-run scene.

When paint fragments are able to be fit back into a source, those fragments may be identified as originating from that specific source. The crime laboratory determined the specific source by analysing vehicle paint samples. The chemical properties of paint are determined through the use of gas chromatography to determine whether samples are from the same source. Thus,paint can be used to establish the sequence of events in hit and run [7-9].

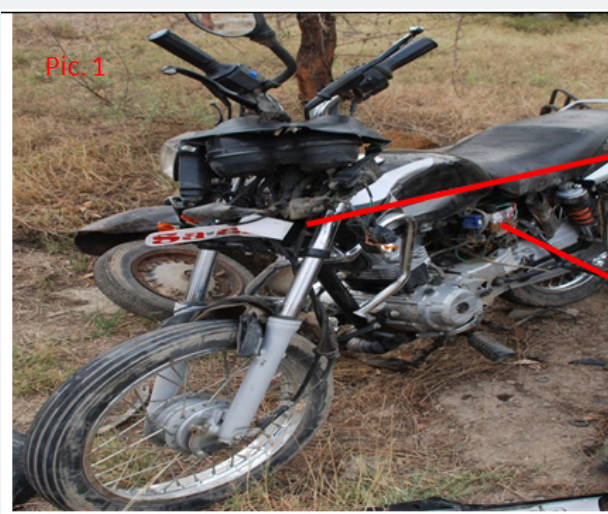

Pic. 1 shows the damaged motorcycle with dented number plate with red coloured letters painted on white painted base.

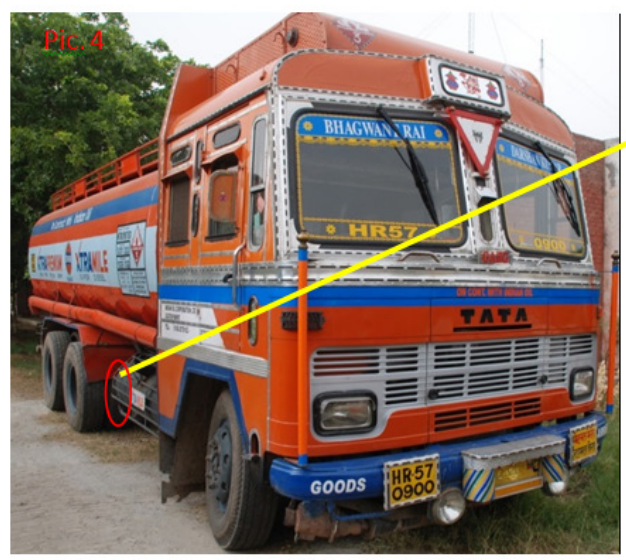

Pic. 4 show the truck that hit the motorcycle and escaped from the spot red and white coloured transfer of paint was detected in red encircled portion of the fuel tank.

\section{उa.6.}

Pic 2 gives the view of the damaged front number plate of the motorcycle mentioned

In pic 1 as indicated by the arrow

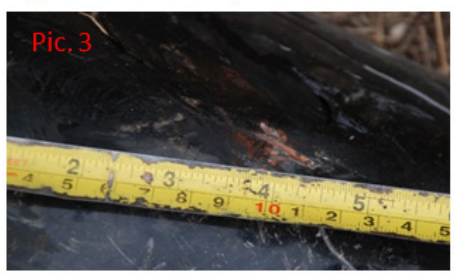

Pic 3 show the Red paint transferred on the battery cover of the motorcycle damaged in the hit and run accident as indiczied by arrow.

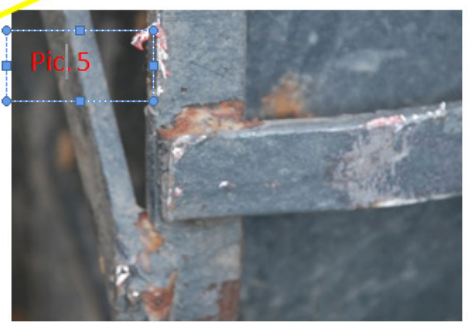

Pic. 5 shows the close view of the red and white paint as found transferred on portion of fuel tank of truck as encircled by red circle in pic 4 and indicated by yellow arrow.

Figure 1 


\section{Case study 1}

One hit and run accident case was reported in district Jind. In this case one motorcycle was found in badly damaged conditions at the scene of accident. In this incident the person riding on the motorcycle was died. The motorcycle was observed to be having red transfer of paint on its damaged and detached battery cover which was collected for comparison with the accused vehicle. A number of vehicles were rounded up later on which were suspected to be involved in the collision. Out of these, one tanker truck as shown in pic 4 was observed to be having red and white transferred paint as indicated in pic 5. This white and red paint was analysed and found to be matching physically and chemically with paint of number plate mentioned in pics 1 and 2. The red paint found on motorcycle as mentioned in pic 3 was analysed and found to be matching physically and comically with the red paint of the tanker truck. Hence it was the paint traced as physical evidence thatlinked the collision of accused vehicle with victim vehicle and hence the case could be solved beyond any doubt (Figure 1).

\section{Case study 2}

An incident was reported to the police in which one vehicle hit a Maruti Ritz car and ran away from the spot. Two young persons died in this tragic accident. In this case scene was visited by my team for crime scene examination. We found a white colour car lying in badly damaged conditions on the southern side of the south bypass road in city Hisar as shown in pic 6. Light brown transfer of paint was noticed on the car as indicated in pic 7 . It was also observed that right side of the car having dents and damages along with graze marks and door handles of both right side doors were broken and missing (pics 6,8,9). One broken piece of door handle was found lying on the spot as shown in pic 10. One broken red glass piece appears to be portion of some broken indicator light cover of some vehicle was also observed to be lying on the spot (pic 13). Later on some vehicles were rounded up by police on Rajgarh road, Hisar. We examined the vehicles and found that one truck as shown in pic 11 was having white transfer of paint (pics 11 and 12) and when this paint was analysed and compared with the white paint of the victim car, it was found exactly matching with it (pics 6, 11 and 12). The brown paint which was found transferred on the car (pic 7) was forensically matched with that of brown paint of accused truck. Also broken red glass piece found on the spot matched physically with that of red partially broken and missing glass indicator cover as shown in pics 11 and 13. In addition to this broken pieces of door handles of car $(6,8,9)$ were found entangled in the footrest of the driver cabin of the truck as indicated in pics 11 and 14. In this way, we linked the vehicle accused of crime of hit and run with the victim's vehicle forensically with the help of trace evidences esp. paint evidence. Thus a case of hit and run which took two precious lives of young person's was solved due to detection and analysis of paint evidence [10-12] (Figure 2).

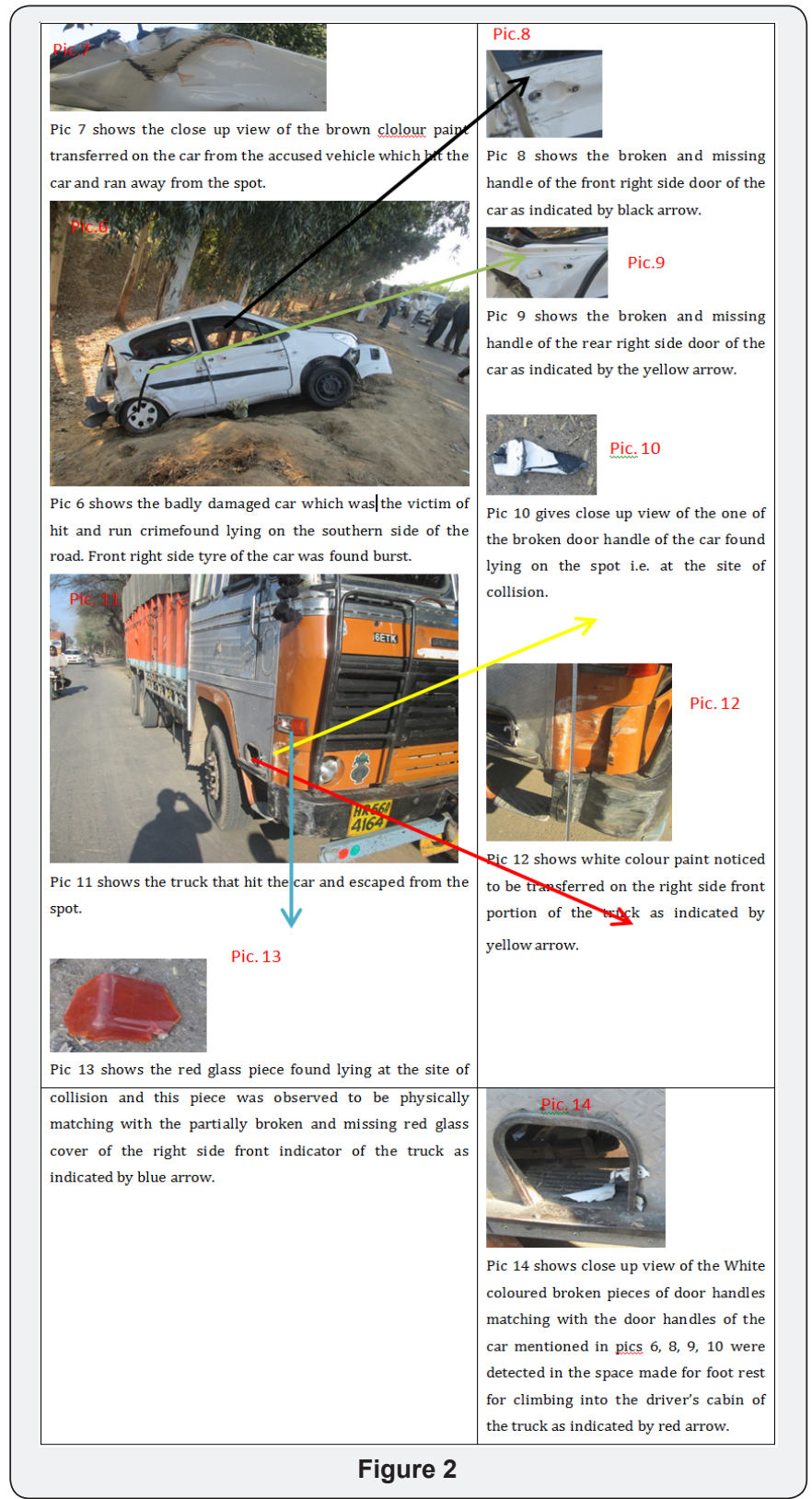

\section{Result and Discussion}

Physical evidences do not tell a lie and neither are influenced by the opinion of others whereas witnesses can and do. Information must be gathered from witnesses, suspects and victims to complete the investigation. Physical evidence always plays an important role in the investigation of any crime. So, never ignore this important stage of the investigation. In many hit-and-run cases there are no eyewitnesses, so physical evidence becomes all important, and the solution of the crime depends on the recognition, protection, collection, identification, and evaluation of this material, As in other types of criminal investigations we work for the identification of the criminal and link him with crime scene through physical evidences he takes from the scene of the crime and physical evidences he leaves at the spot of occurrence [13]. 
Often the materials collected need little or no further examination to establish their connection with the investigation as described in above mentioned case studies. Moreover, large parts of fenders, accessories, lights, etc., can sometimes be matched with the naked eye, or with ordinary photographs. At other times the minute pieces of paint, glass, etc. are subjected to more precise examination, using the tools of modern science, to establish their similarity or in some cases their dissimilarity (as mentioned in the case studies 1 \& 2).

\section{Conclusion}

When the suspect's vehicle was located, we reviewed the facts obtained from the investigation of the scene and the victim's vehicle. We detected the exchange of physical evidences e.g. paint between the vehicles involved in the collision as well as physical evidence present on the spot of accident and solved the hit and run cases as mentioned in case studies. In this paper, we have mentioned the materials i.e. the physical evidences esp. paint evidences which have been useful in identifying hit-andrun vehicles. If these paint traces are identified to the original source, viz. the criminal's vehicle (or vice versa) they establish the contact and pin the crime down to the criminal. In hit and run case clues like exchange of paint establishes the identity of the culprit vehicle. While investigating similar cases and probably others which we have not mentioned here, one should remember to consider everything found at the scene, on the victim/victim's vehicle, or on the suspect's vehicle as potential physical evidence subject to identification or comparison with other material found during the investigation and we must remember to handle each of the above mentioned evidences in such a manner that these may be acceptable in court while corroborating with other testimonies. In this way aim and objective of our paper will be achieved.

\section{References}

1. Domke, Ellen, Klepitsch J (1993) Hit-Run: A Crash Course, 120-a-Day in Chicago: Problem in Suburbs: Chicago Sun Times, USA.

2. Sharma M, Jha S (2012) Forensic examination of hit-n-run cases: A study proceedings of First International Conference on Law and Forensics: 243-249.

3. Tpac Acciment Investigators Manual, The Traffic Institute of North western University, Evanston, Illinois, USA.

4. Kiely TF (2005) Forensic Evidence: Science and the criminal law (2nd edtn.) CRC Press, Florida, USA.

5. Adams TF, Krutsinger J (2000) Crime Scene Investigation Prentice Hall.

6. Domke, Ellen, Klepitsch J (1993) Hit-Run: A Crash Course, 120-a-Day in Chicago: Problem in Suburbs: Chicago Sun Times, USA.

7. Vallejo CA, Edsicker D (2001) Crime Scene Investigation and Physical Evidence Manual.

8. http://www.atlantaeng.com/sceneinvestigation.html

9. https://www.nist.gov/sites/default/files/documents/forensics/ Crime-Scene-Investigation.pdf

10. http://www.actforlibraries.org/paint-as-a-evidence-in-a-forensicinvestigation/

11. https://archives.fbi.gov/archives/about-us/lab/forensic-science communications/fsc/april2000/twgcsi.pdf

12.https://www.faa.gov/about/initiatives/maintenance_hf/library/ documents/media/hfacs/2_accidentinvestigation.pdffile:///J:/ current $\% 20$ desktop $\% 20$ item $\% 2014$

13. ballistic\%20test $\% 20$ firing\%20equipments/ accident $\% 20$ case $\% 20$ studies/2014-06-04-Accident-Investigation-Manual-optimized_opt. pdf.

\section{Your next submission with Juniper Publishers}

will reach you the below assets

- Quality Editorial service

- Swift Peer Review

- Reprints availability

- E-prints Service

- Manuscript Podcast for convenient understanding

- Global attainment for your research

- Manuscript accessibility in different formats

( Pdf, E-pub, Full Text, Audio)

- Unceasing customer service

Track the below URL for one-step submission https://juniperpublishers.com/online-submission.php 